\title{
SOSIALISASI PENGENALAN HEWAN PENYU LAUT MELALUI PERMAINAN MENARIK BAGI ANAK SEKOLAH DASAR SDN ALUE PIET GAMPONG ALUE PIET
}

\section{THE SOCIALIZATION OF SEA TURTLE INTRODUCTION THROUGH INTERESTING GAMES FOR ELEMENTERY SCHOOL STUDENT SDN ALUE PIET ALUE PIET VILLAGE}

\author{
Mohamad Gazali ${ }^{1}$ \\ ${ }^{1}$ Prodi Manajemen Sumberdaya Akuatik Fakultas Perikanan dan IImu Kelautan Universitas Teuku Umar \\ Korespondensi : mohamadgazali@utu.ac.id
}

\begin{abstract}
ABSTRAK
Konservasi merupakan salah satu kegiatan yang diharapkan dapat mencegah punahnya habitat penyu, mencegah adanya pemanfaatan penyu demi kepentingan komersial seperti penjualan telur, daging, maupun cangkang dan dapat menjadi sarana berbagi ilmu atau edukasi kepada masyarakat secara luas tentang pentingnya konservasi penyu demi menjaga habitat penyu di Indonesia agar tidak punah. Sasaran masyarakat yang akan dilibatkan sosialisasi pengenalan penyu laut melalui permainan menarik yaitu siswa/siswi SDN Alue Piet. Berdasarkan hasil wawancara bahwa masih banyak anak-anak yang tinggal di wilayah pesisir Panga Pasie masih merasa asing dengan penyu laut. Diantara mereka pernah menemukan penyu di wilayah pesisir pada pagi hari merasa ketakutan dengan makhluk yang masih terlihat asing. Oleh karena itu, kami melaksanakan kegiatan pengabdian kepada masyarakat melalui sosialisasi pengenalan penyu dengan media permainan yang menarik. Kegiatan pengabdian kepada masyarakat tersebut meliputi survei sekolah dasar yang berdekatan dengan lokasi peneluran penyu, sosialisasi pengenalan penyu melalui pemutaran video animasi penyu, Quiz dan melakukan penyusunan puzzle bergambarkan penyu. Seluruh kegiatan pengabdian kepada masyarakat berjalan tepat pada waktunya dan mendapatkan dukungan dari pihak sekolah SDN Alue Piet.
\end{abstract}

Kata kunci : Sosialisasi, Penyu laut, Permainan, Siswa/Siswi

\section{ABSTRACT}

Conservation is one of the activity that hope to prevent the sea turtle are scarce, to prevent sea turtle utilization for commercial interest such as sold the eggs, flesh, as well as carapaces and become sharing knowledge facility or education for community widely regarding the importance of sea turtle conservation for keeping sea turtle habitat in Indonesia in order it is not scarce. The target of communities are elementary school student SDN Alue Piet. According to the interview that many student that inhabited in Panga Pasie Coastal area still feel strange with sea turtle. Among of them ever found it in the coastal area on the morning to feel fearness with this creature that appeared strange. Therefore, we conduct the community serving through the socialization of sea turtle introduction with interesting of media game. The community serving including surveying of elementary school that approach with nesting site, socialization of sea turtle introduction through video sea turtle animation, doing of Quiz, and undertaken arrangement of sea turtle puzzle picture. Overall activities of community serving undergone on time and obtained supporting from SDN Alue Piet organizer.

Keyword : Socialization, sea turtle, game, elementary student

\section{PENDAHULUAN}

Indonesia merupakan Negara Kepulauan terbesar di dunia dengan jumlah pulau lebih dari 17.500 di sepanjang ekuator dan lebih dari 360 juta hektar area laut. Terhampar diantara isothermal $20^{\circ} \mathrm{LU} / \mathrm{LS}$ merupakan lokasi yang baik bagi 
pertumbuhan terumbu karang, rumput laut dan keanekaragaman hayati termasuk penyu laut (Limpus dan Mc Lachian, 1996).

Penyu telah mengalami penurunan jumlah populasi dalam jangka waktu terakhir ini bahkan beberapa spesies terancam kepunahan. Di alam, penyu-penyu yang baru menetas menghadapi ancaman kematian dari hewan-hewan seperti kepiting, burung, dan reptilia lainnya seperti biawak. Ancaman yang paling besar bagi penyu di Indonesia, seperti juga halnya di seluruh dunia, adalah manusia. Pembangunan daerah pesisir yang berlebihan telah mengurangi habitat penyu untuk bersarang. Penangkapan penyu untuk diambil telur, daging, kulit, dan cangkangnya telah membuat populasi penyu berkurang. Semua penyu menurut Sukresno (1997) telah terdaftar dalam Daftar Apendik I CITIES (Convension on International Trade of Endangered Species). Konvensi ini melarang semua perdagangan internasional atas semua produk yang berasal dari penyu, baik itu berupa telur, daging, maupun cangkangnya.

Berdasarkan peraturan perundang-undangan jenis Penyu Belimbing dilindungi berdasarkan SK Menteri Pertanian No.327/Kpts/Um/5/1978; Penyu Tempayan dan Lekang dilindungi berdasarkan SK Menteri Pertanian No.716/Kpts/Um/10/1980; Penyu Sisik dan Penyu Pipih dilindungi berdasarkan SK Menteri Kehutanan No. 882/KptsII/1992, dan Penyu Hijau yang termasuk dalam 6 jenis penyu yang dilindungi berdasarkan PP No.7/1999 tentang pengawetan tumbuhan dan satwa.

Konservasi merupakan salah satu kegiatan yang diharapkan dapat mencegah punahnya habitat penyu, mencegah adanya pemanfaatan penyu demi kepentingan komersial seperti penjualan telur, daging, maupun cangkang dan dapat menjadi sarana berbagi ilmu atau edukasi kepada masyarakat secara luas tentang pentingnya konservasi penyu demi enjaga habitat penyu di Indonesia agar tidak punah.

Berdasarkan World Conservation Union (IUCN), pengertian dasar dari kawasan konservasi adalah "Luas lahan daratan dan/atau laut terutama yang diperuntukan untuk perlindungan dan pemeliharaan keanekaragaman hayati, dan sumber daya alam yang terhubung dengan budaya yang terkait, dan dikelola melalui penerapan hukum atau dengan cara efektif lainnya" (Broquere, 2005). Dari pengertian kawasan konservasi sebagai "luas lahan daratan dan/atau lautan" dan juga berdasarkan pengkategorian kawasan konservasi, maka Kawasan Konservasi Laut dianggap sebagai bagian dari sistem kawasan konservasi secara keseluruhan. Dengan demikian dapat dikatakan bahwa Kawasan Konservasi Laut merupakan bagian dari upaya pengelolaan atau konservasi ekosistem.

Menurut Pomeroy (2012) keberadaan KKL dapat melindungi ekosistem secara keseluruhan, karena melalui konservasi dapat melindungi spesies yang menjadi target eksploitasi dari kepunahan sekaligus melindungi kondisi habitat yang penting seperti daerah pemijahan dan pemeliharaan spesies tersebut. Pembentukan kawasan konservasi perairan khususnya perairan laut sering belum diiringi dengan pengelolaan yang efektif. Kenyataan yang banyak terjadi di lapangan menunjukkan bahwa pengelolaan sumber daya perikanan di kawasan konservasi laut tidak cukup hanya memerhatikan kelestarian lingkungan saja, namun seharusnya juga memerhatikan kesejahteraan masyarakat. Kencenderungan diatas dikarenakan kurang optimalnya pengelolaan kawasan konservasi laut yang disebabkan antara lain oleh: 1) Orientasi pengelolaan kawasan konservasi laut lebih fokus pada manajemen teresterial; 2) 
Pengelolaan bersifat sentralistik dan belum melibatkan masyarakat setempat; 3) Tumpang tindih pemanfaatan ruang dan benturan kepentingan para pihak; dan 4) Banyaknya pelanggaran yang terjadi di kawasan konservasi laut. Menurut Reefbase (2006), lebih dari $100 \mathrm{KKL}$ yang tercatat di Indonesia, sebagaian besar diantaranya tidak memiliki rencana pengelolaan formal yang siap, mencerminkan fakta bahwa ekosistem laut umumnya telah diberikan prioritas yang lebih rendah dibandingkan dengan daerah teresterial.

\section{Permasalahan}

Kecamatan Panga mempunyai luas wilayah terkecil yaitu sekitar $8 \%\left(307 \mathrm{~km}^{2}\right)$ dari wilayah Kabupaten. Secara geografis Kecamatan-Kecamatan di wilayah Kabupaten Aceh Jaya berbatasan langsung dengan Samudera Hindia dimana jalur sepanjang pantai juga merupakan tempat permukiman penduduk terpadat dibandingkan dengan daerah pemukiman yang jauh dari pantai. Wilayah tesebut merupakan lokasi peneluran telur. Terdapat tiga (3) Desa Pesisir yang yang telah teridentifikasi sebagai areal peneluran penyu (nesting site), yaitu Desa Keude Panga, Kuta Tuha dan Alue Piet.

Berdasarkan hasil survei bahwa masih banyak anal-anak belum mengenal penyu laut. Mereka cenderung tidak bisa membedakan antara kura-kura dengan penyu laut. Beberapa di antara mereka yang pernah menemukan penyu di kawasan pesisir Panga Pasie namun mereka ketakutan melihat penyu yang lagi turun ke laut pasca bertelur. Hal ini menjadi urgensi kegiatan pengabdian kepada masyarakat yang dilaksanakan di SDN 1 Alue Piet dengan memperkenalkan satwa langka yang disebut dengan penyu laut. Kami memberikan edukasi pengenalan penyu kepada anak-anak SDN 1 Alue Piet dengan menyajikan video kartun dan permainan yang menarik bagi anak-anak.

\section{Tujuan Pelaksanaan}

Tujuan pelaksanaan kegiatan pengabdian kepada masyarakat ini adalah sebagai berikut :

1. Memberikan pemahaman dan pengetahuan kepada siswa/siswi SDN Alue Piet tentang penyu laut

2. Membangun silaturahmi pihak sekolah SDN Alue Piet sebagai tempat lokasi pengabdian kepada masyarakat.

3. Mendorong siswa/siswi SDN Alue Piet untuk antusias menggerakkan konservasi penyu secara dini melalui edukasi dini. 


\section{METODE PELAKSANAAN Tempat dan Waktu}

Pelaksanaan kegiatan ini telah dilaksanakan pada tanggal 5-10 Agustus 2017 di Shelter Konservasi Penyu Gampong Keude Panga Kecamatan Panga Kabupaten Aceh Jaya Propinsi Aceh (Gambar 3).

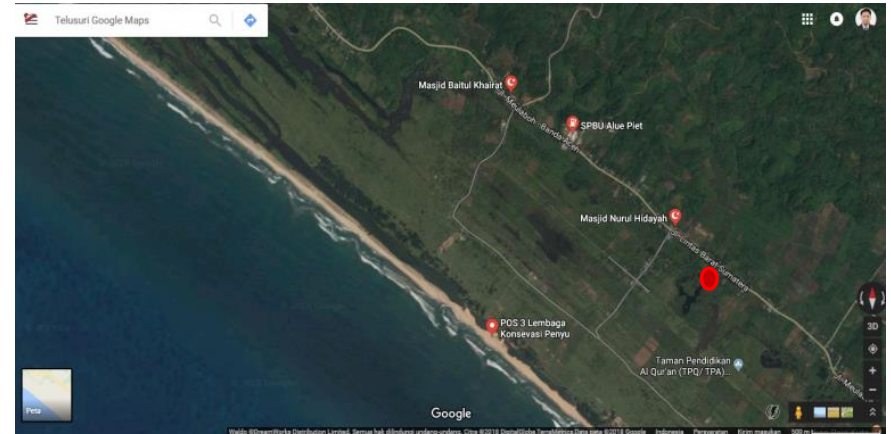

Gambar 1. Peta Lokasi Kegiatan Pengabdian kepada Masyaraka) ( )

\section{Teknik Pelaksanaan}

Metode pelaksanaan dengan menggunakan teknik penyuluhan secara langsung yaitu sosialisasi konservasi penyu dari Sekolah Dasar (SD). Bentuk sosialisasi penyu dengan pendekatan edukasi sangat tepat untuk menumbuhkan kesadaran masyarakat pesisir dan generasi muda dalam mempertahankan populasi penyu tetap lestari. Adapun tahapan pekerjaan dalam menyelesaikan permasalahan dan sekaligus pencapaian tujuan program adalah sebagai berikut :

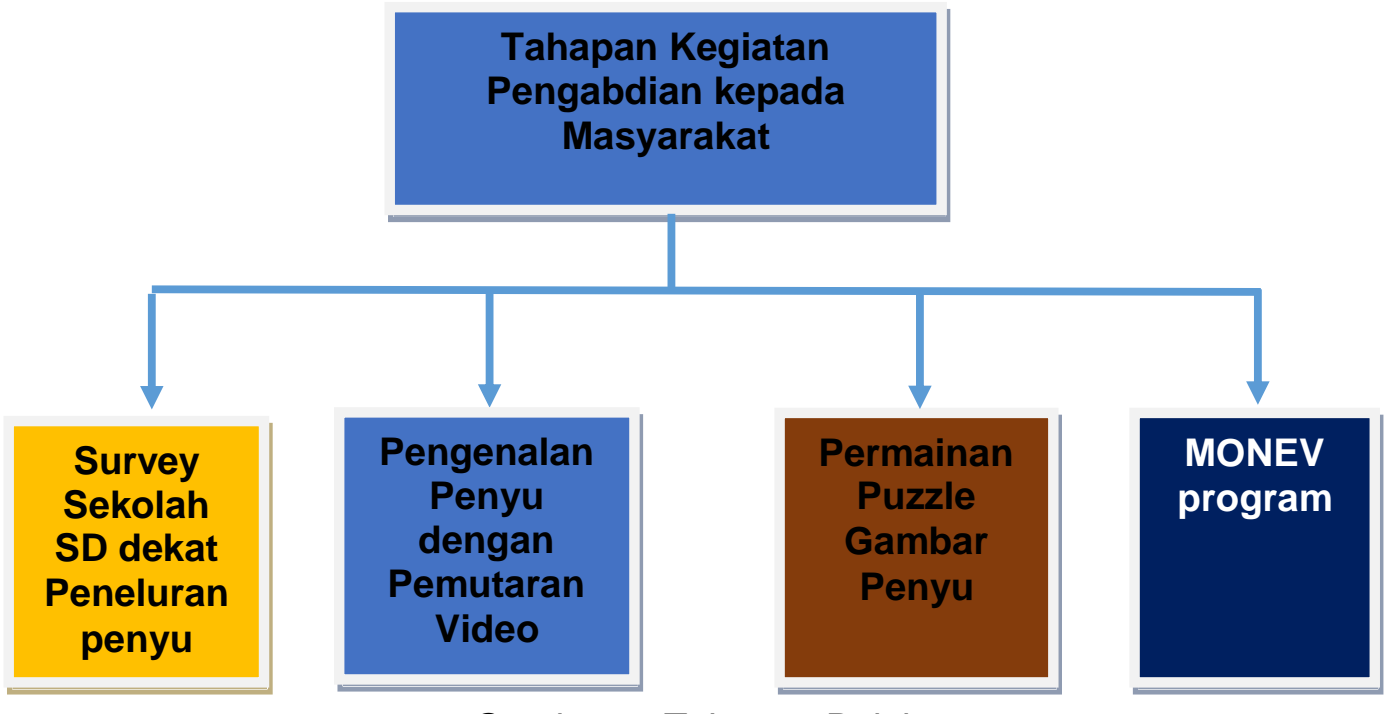

Gambar 2. Tahapan Pelaksanaan

\section{HASIL DAN PEMBAHASAN}

\section{Pemutaran Video kepada Anak-Anak SDN Alue Piet}

Pelaksanaan sosialisasi penyu di SDN Alue Piet dilaksanakan pada bulan Mei 2016. SDN Alue Piet merupakan sosialisasi yang kedua dan metode penyuluhan yang digunakan yaitu banyak memberikan edukasi melalui ceramah dan pemutaran video animasi tentang kehidupan penyu di alam liar. 
Dalam proses pemutaran video animasi penyu, kami menyajikan konten-konten tentang pola kehidupan penyu di alam dan menyisiplan pesan-pesan moral akan pentingnya menjaga penyu dari kepunahan akibat predator dan perburuan serta pencemaran laut. Hal ini mensugesti alam bawah sadar anak-anak dengan penghayatan yang mendalam sehingga dapat tersimpan dalam memori anak-anak.

Kami memilih sekolah SDN Alue Piet karena merupakan salah satu sekolah yang berdekatan dengan lokasi habitat peneluran penyu. Beberapa program yang sudah dilakukan lembaga konservasi penyu Aroen Meubanja dengan melibatkan anak-anak dalam pengenalan hewan penyu laut.

Video animasi yang diberikan dalam sosialisasi tersebut juga menggambarkan proses perkembangbiakan di alam sampai penyu mengalami kedewasaan. Metode penyuluhan tersebut sangat efektif menarik minat siswa/siswi dalam mengenal dan merespon konservasi penyu yang ada di Wilayah Pesisir Panga (Aceh. Siswa/siswi sangat antusias dalam mengikuti kegiatan sosialisasi melalui pemutaran video animasi (Gambar 3).

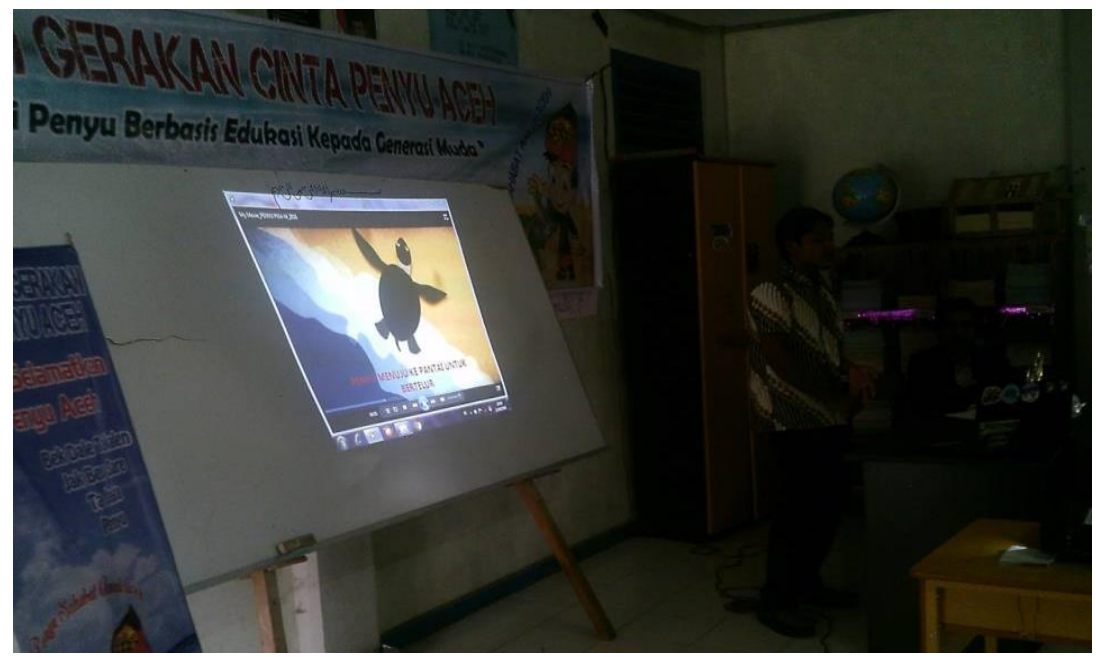

Gambar 3. Pemutaran Video Animasi

Sumber : (Dokumentasi Lapangan, 2016).

Anak-anak adalah generasi penerus bangsa, maka harus dibekali dengan pengetahuan yang memadai. Kita sebagai seorang pendidik membekali mereka dengan pengetahuan konservasi penyu agar kedepan mereka dapat mempertahankan keberlangsungan konservasi penyu. Salah satu pondasi yang sangat penting untuk menjadikan Negara kuat, maju dan sejahtera adalah dengan menjadikan anak-anak sebagai aset masa depan.

Dalam kegiatan pengabdian kepada Masyarakat, kami melibatkan Guru SDN Alue Piet dalam kegiatan tersebut. Setelah pemutaran video animasi penyu, kami mengevaluasi pemahaman siswa/siswi dengan memberikan pertanyaan seputar video animasi kepada siswa/siswi SDN Alue Piet. Kami memberikan penilaian melalui kecepatan dan ketepatan dalam menjawab pertanyaan juri. Perlombaan tersebut berupa kuis pemutaran video animasi penyu. Kami menyiapkan piala untuk Juara 1, Juara 2 dan Juara 3. Selain itu, kami juga memberikan pakaian kaos bergambarkan penyu sahabat aneuk Aceh (Gambar 4). 


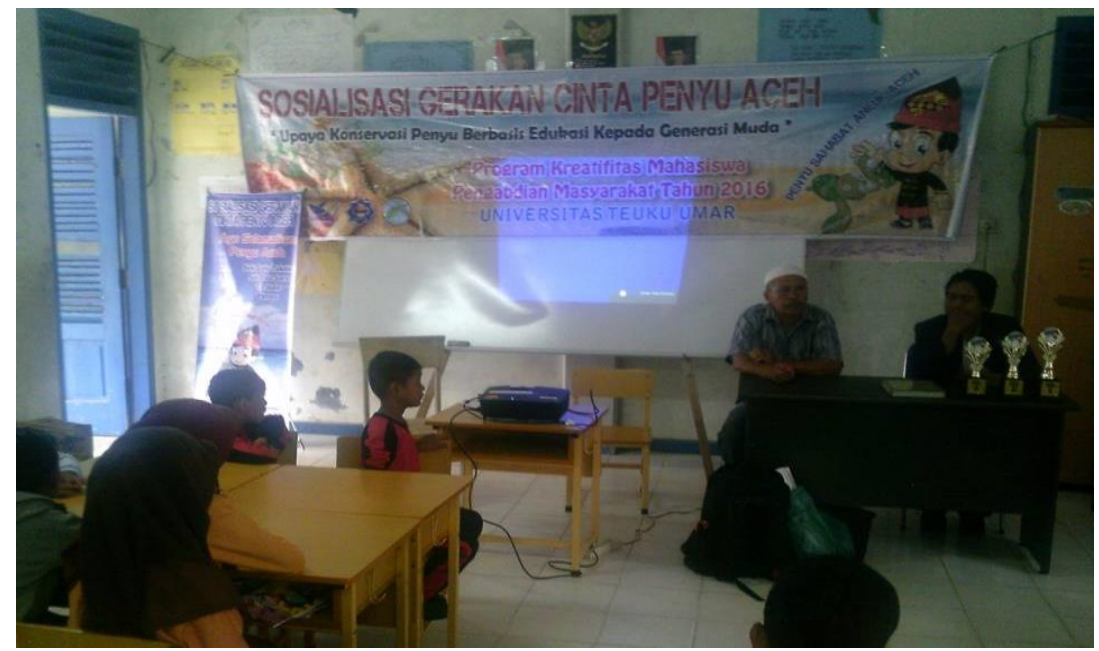

Gambar 4. Penilaian Perlombaan Quiz siswa/siswi SDN Alue Piet Sumber : (Dokumentasi Lapangan, 2016).

\section{Permainan Menarik (Fun Games)}

Dalam kegiatan pengabdian kepada masyarakat kami memberikan sebuah permainan dengan menguji kekompakan bagi siswa/siswi di SDN 4 Alue Piet yaitu menyusun puzzle bergambarkan penyu. Selanjutnya, diseleksi kembali untuk mendapatkan hadiah per individu yaitu berupa Piala dan kaos Penyu.(Gambar 5).

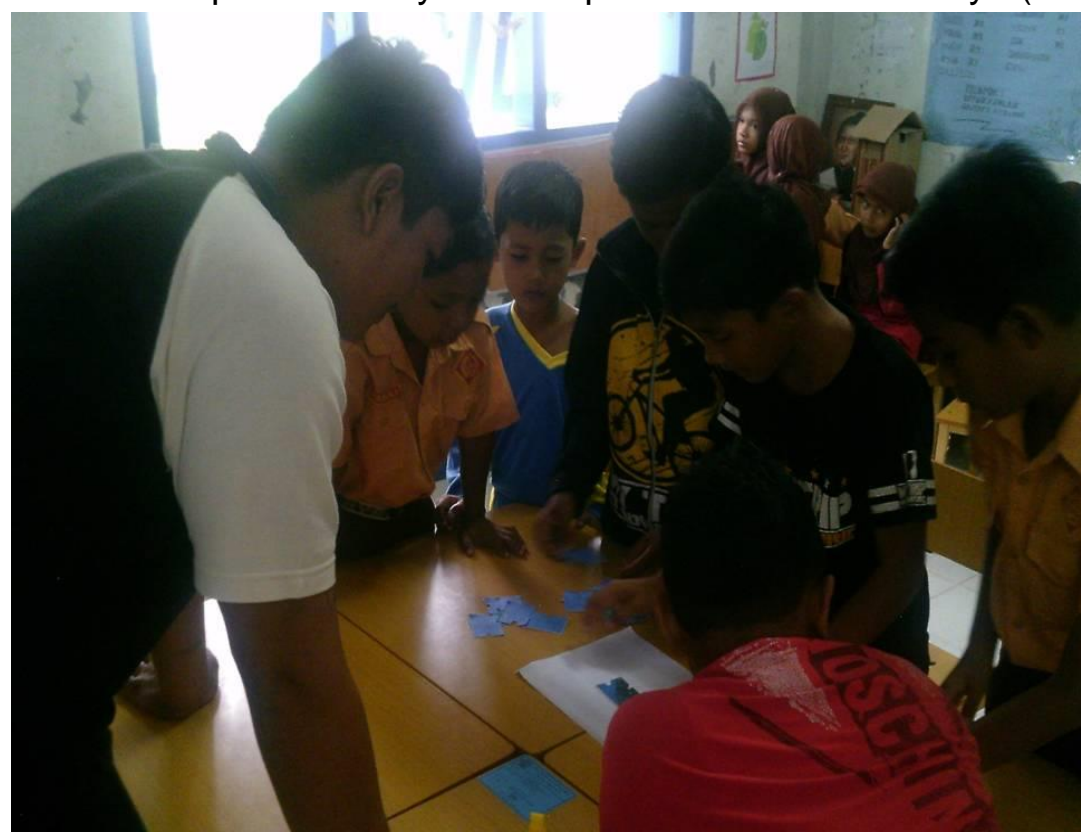

Gambar 4. Lomba Puzzle Gambar Penyu

Sumber : (Dokumentasi Lapangan, 2016).

Dalam perlombaan puzzle gambar penyu, siswa/siswi SDN Alue Piet memperlihatkan rasa antusias dalam mengikuti perlombaan tersebut. Tujuan melaksanakan perlombaan puzzle gambar penyu bagi anak-anak adalah untuk menanamkan kreativitas kepada anak-anak. Penyajian audiovisual merupakan langkah yang efektif dan efisien dalam metode pembelajaran (learning method). Hal ini melatih 
otak kanan anak-anak dalam menumbuhkembangkan pemahaman pengenalan penyu laut (Gambar 5).

Otak kanan memiliki kemampuan untuk merekam ingatan dengan cepat sekaligus menyimpan ingatan tersebut di dalam memori dalam jangka waktu yang lama dalam otak. Otak bagian kanan juga bisa mengatur segala masalah pemikiran yang berkaitan dengan imajinasi dan kreativitas. Bagi Anda yang ingin anak berkembang kemampuan otak kanannya, maka wajib mengetahui cara melatih otak kanan pada anak.

Anak yang otak kanannya lebih mendominasi bisanya suka dengan hal-hal yang sifatnya abstrak, seni dan acak. Otak kanan memudahkan manusia untuk mempelajari semua bagian secara keseluruhan, menyukai gambar, menyukai grafik, bagan, menyukai sistem keseluruhan bahasa, dan hal-hal baru lainnya. Anak yang otak bagian kanannya lebih dominan, biasanya sangat pandai bergaul dan bersosialisasi.

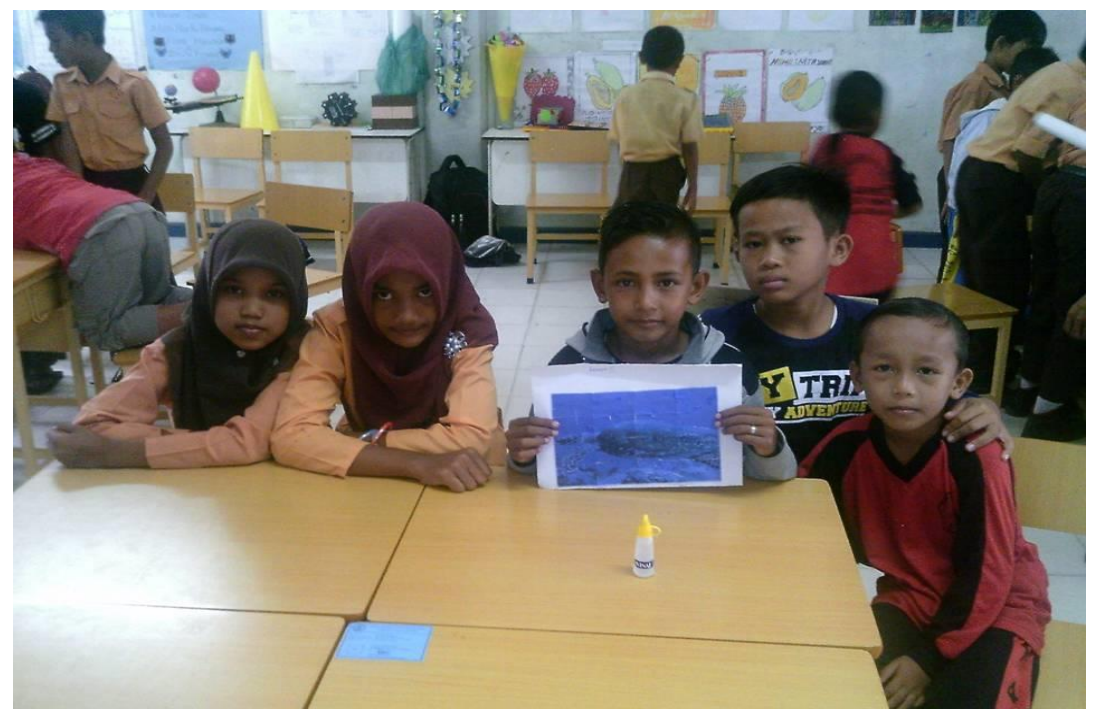

Gambar 5. Hasil puzzle bergambarkan Penyu Laut Sumber : (Dokumentasi Lapangan, 2016)

\section{Penyerahan Hadiah bagi Pemenang Lomba}

Dalam perlombaan yang dirangkaian melalui Quiz pemutaran video animasi penyu dan lomba menyusun puzzle bergambarkan penyu. Maka terdapat tiga orang sebagai juara. Selanjutnya, berdasarkan hasil penilaian juri lomba dengan melalui berbagai perlombaan yang diikuti secara individual dan kelompok siswa/siswi SDN Alue Piet. Pada saat penyerahan hadiah dimana diserahkan langsung oleh lbu Wakasek SDN Alue Piet. Anak-anak siswa/siswi SDN Alue Piet merasa bangga dengan perolehan. Hal ini bertujuan untuk mempersiapkan generasi yang peka terhadap lingkungan terutama habitat beserta satwa langka (penyu) yang merupakan wilayah dimana mereka tinggal (Gambar 6). 


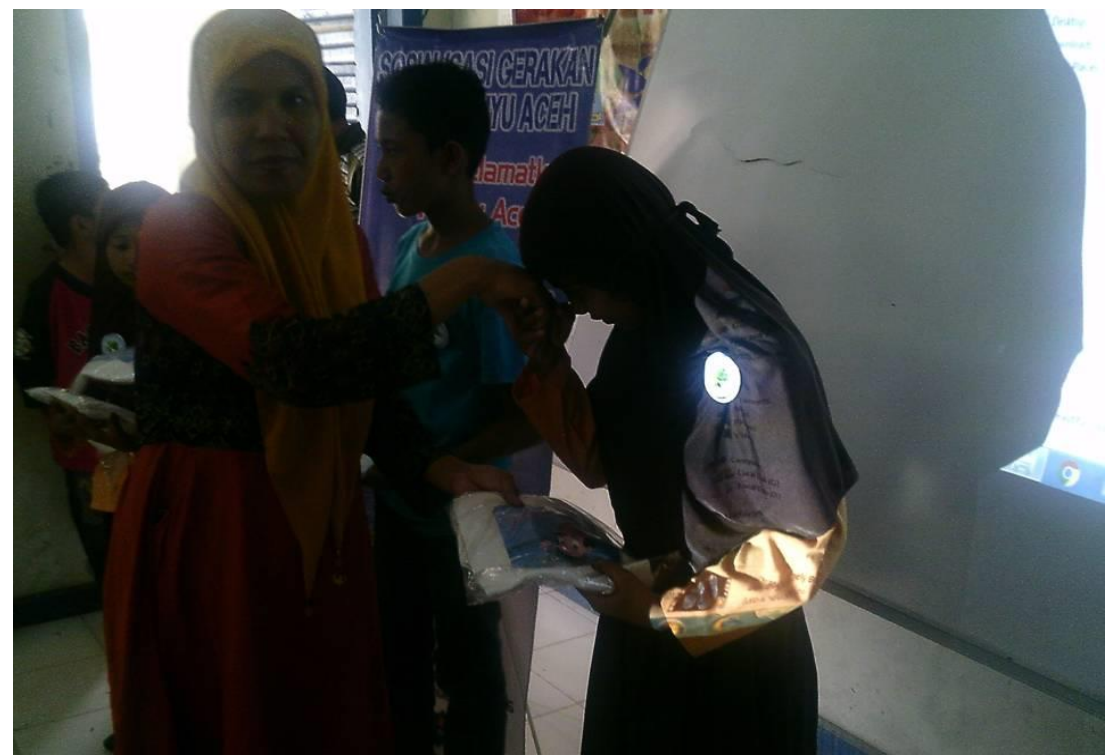

Gambar 6. Penyerahan hadiah oleh Wakasek SDN Alue Piet Sumber : (Dokumentasi Lapangan, 2016).

\section{Berpose bersama Pasca Kegiatan Pengabdian kepada Masyarakat}

Setelah kegiatan pengabdian kepada masyarakat selesai dilakukan maka kami sebagai bentuk kebersamaan kami berfoto bersama siswa/siswi SDN Alue Piet beserta guru-guru. Berdasarkan hasil wawancara dari pihak sekolah bahwa mereka sangat mengapresiasikan kegiatan pengabdian kepada masyarakat. Hal ini bertujuan menanamkan rasa kepedulian terhadap penyu laut yang berada di kawasan pesisir panga. Kedepan, mereka berharap kegiatan ini masih berlanjut dengan model yang berbeda (Gambar 7).

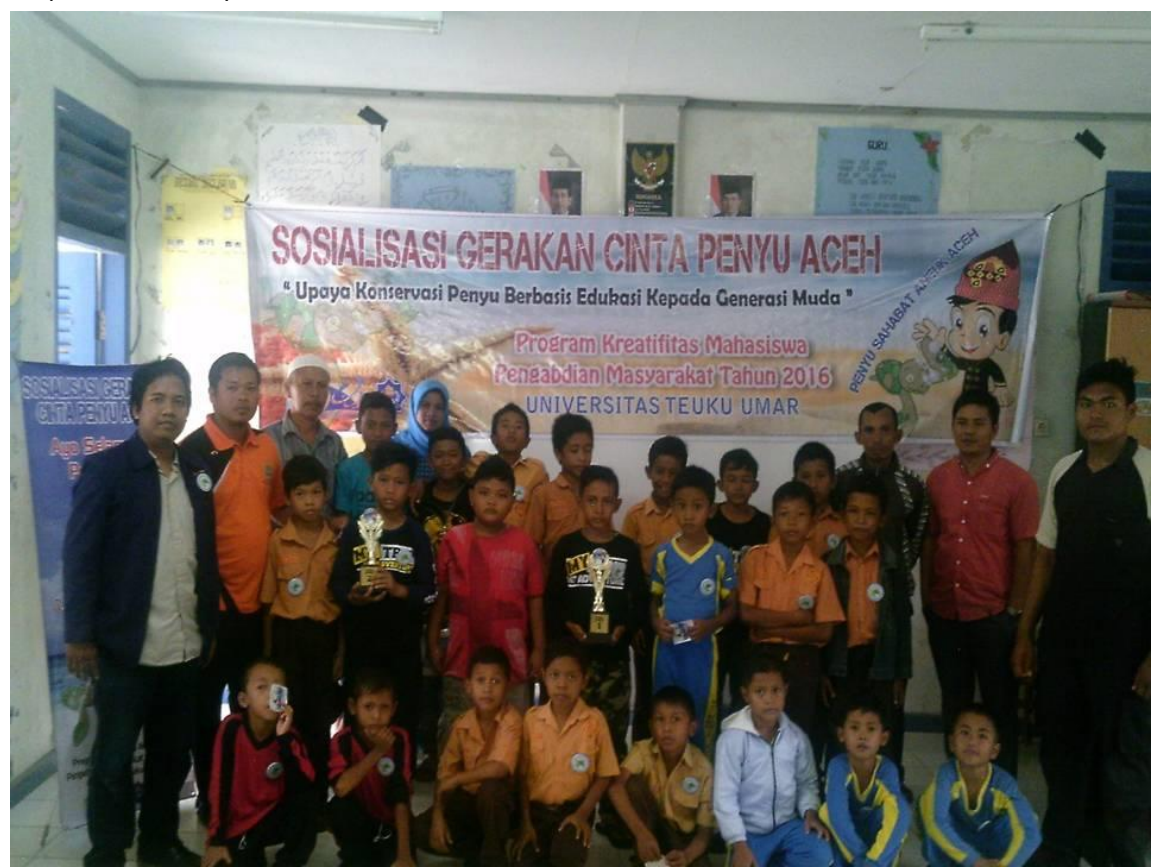

Gambar 7. Foto bersama guru dan siswa/i SDN Alue Piet

Sumber : (Dokumentasi Lapangan, 2016) 


\section{SIMPULAN DAN SARAN}

\section{Simpulan}

Berdasarkan hasil dan pembahasan di atas disimpulkan bahwa kegiatan pengabdian kepada masyarakat meliputi sosialisasi melalui pemutaran video animasi penyu, QUIZ dan perlombaan penyusunan puzzle bergambarkan penyu laut. Dalam kegiatan pengabdian kepada masyarakat tersebut berjalan dengan baik dan lancar. Siswa/siswi begitu antuasias mengikuti program pengabdian kepada masyarakat dan mendapat dukungan penuh dari pihak sekolah SDN Alue Piet.

\section{Saran}

Perlu adanya sosialisasi pengenalan penyu di Sekolah Dasar (SD) lainnya yang berdekatan dengan daerah peneluran penyu seperti SDN 1 Panga dan SDN Kuta Tuha agar kegiatan sosialisasi tersebut tersebar merata di wilayah kawasan konservasi penyu melalui kerjasama dengan Lembaga Konservasi Penyu Aroen Meubanja.

\section{UCAPAN TERIMA KASIH}

a. Dalam mensukseskan kegiatan pengabdian kepada masyarakat ini tidak terlepas dari kerjasama yang baik dari Tim Konservasi Penyu Aroen Meubanja (Bapak Murniadi). Atas kerjasama dan kekompakan dalam kegiatan sosialisasi konservasi penyu Aroen Meubanja Kami ucapkan terima kasih yang setinggitingginya

b. Mahasiswa Program Kreativitas Mahasiswa (PKM) yang lolos pendanaan tahun 2016 yang ikut serta dalam kegiatan konservasi penyu bersama Lembaga Konservasi penyu Aroen Meubanja.

\section{DAFTAR PUSTAKA}

Broquere M. 2005. "How many marine protected areas exist in the West Mediterranean?" IUCN Centre for Mediterranean Cooperation. Available at http://www.iucn.org/places/medoffice/documentos/Rapport final AMP en.pdf.

Limpus, C.J. and McLachlan, N. 1996. The conservation status of the leatherback turtle, Dermochelys coriacea, in Australia. In R. James, ed. Proc. Marine Turtle Conservation Workshop, pp. 6872. Canberra, Australia, Australian National Parks and Wildlife Service.

Pomeroy RS. 2012. Managing over capacity in smallscale fisheries in South East Asia. Marine Policy. 36(2): 520527.

Reefbase. 2006. Webpage. Available at: http://www.reefbase.org/management/ man_gaps. 